\title{
Intestinal Research Is Now Registered in PubMed Central
}

\author{
Suk-Kyun Yang \\ Publisher, Intestinal Research; President, Korean Association for the Study of Intestinal Diseases. \\ Department of Gastroenterology, Asan Medical Center, University of Ulsan College of Medicine, Seoul, Korea
}

In the 1990s, only a small number of physicians in Korea were interested in the field of intestinal diseases, mainly because of the low incidence of colorectal cancers and IBDs in Asian countries, including Korea. Nonetheless, pioneers from multiple centers started a small meeting of research groups in 1998, and finally founded an official society named the "Korean Association for the Study of Intestinal Diseases (KASID)" in 2002. In order to expand knowledge and remain up-to-date, KASID intended to hold academic exchanges with international societies. Building on the experience of the Korea-Japan IBD symposia from 2006 to 2012, KASID, together with IBD societies of China and Japan, founded the Asian Organization for Crohn's and Colitis (AOCC) as one of the world's principal societies in 2013, and held the second annual meeting of the AOCC in 2014. In the field of colorectal neoplasia, the biennial international symposium on colorectal neoplasia started in 2013.

Intestinal Research (Intest Res) was first issued in 2003 as the official journal of KASID, and its growth has paralleled the growth of KASID itself. At the time of this journal's birth, the founding members had its expansion as an international academic journal in mind, and thus the name Intest Res does not contain any words indicating a certain region or country. Even with these intentions, Intest Res has been published in Korean as a purely domestic medical journal to expand and solidify the domestic knowledge base of lower gastrointestinal diseases until 2013. However, to keep up

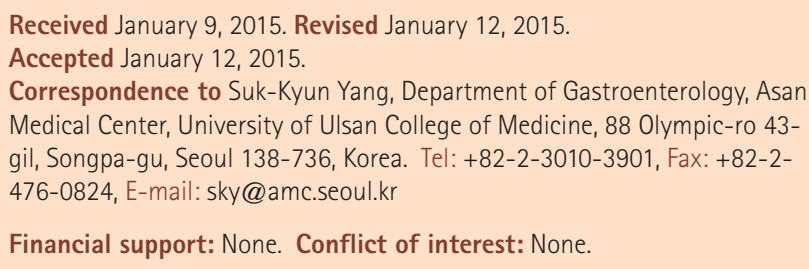

with international trends and to achieve success in international communication, Intest Res was converted to a fully English journal from the first issue of 2014 (Volume 12, Issue 1), and the journal's English homepage (www.irjournal.org) was launched. At present, Intest Res serves as the joint official publication of KASID and the Taiwan Society of Inflammatory Bowel Disease.

Recently, Intest Res was proud to participate in PubMed and PubMed Central (PMC), which are the most prestigious platforms for worldwide medical and biological communication. PMC is a free digital database of full-text literature in the biomedical and life sciences. Therefore, readers can search for Intest Res articles in PubMed and read the full contents of articles from Volume 12, Issue 1, 2014.

Intest Res is now fully covered by PubMed, PMC, EBSCO, KoreaMed, Synapse, KoMCI, CrossRef and Google Scholar. This is the first step towards making Intest Res an international journal, and I appreciate the devotion of all past and current members of the Editorial committee. I also would like to thank all the authors who submitted their papers to this growing journal. As our next step, we intend to ensure that Intest Res is indexed as a Science Citation Index Expanded journal, and we need the participation of future authors and readers in addition to the efforts of the future Editorial committee. However, "success is a journey, not a destination," and there is no final destination for this expanding journal. Now, with its English publication and PMC registration, Intest Res has just started its journey to becoming a key scientific journal in the field of intestinal diseases.

๑ Copyright 2015. Korean Association for the Study of Intestinal Diseases. All rights reserved.

This is an Open Access article distributed under the terms of the Creative Commons Attribution Non-Commercial License (http://creativecommons.org/licenses/by-nc/3.0) which permits unrestricted non-commercial use, distribution, and reproduction in any medium, provided the original work is properly cited. 